\title{
Cuentas y cultura material: La reconstrucción del Real Palacio de Lima después del terremoto de 1746
}

\author{
Charles Walker \\ y Ricardo Ramírez Castañeda \\ Universidad de California, Davis, \\ y Universidad de San Marcos, Lima
}

Este artículo es un análisis y transcripción de un libro de cuentas referente a la reconstrucción del Palacio Real en Lima, después del devastador terremoto de 1746. El documento contiene detallada información sobre la procedencia y el costo de la mano de obra y los productos utilizados en dicha obra, información poco común en la documentación de la época. Ofrece así una entrada a una serie de temas importantes para el Perú del XVIII. Estos incluyen la cultura material, la vida y muerte de los esclavos, y las formas de construcción. Contribuye al conocimiento de la historia social y económica del Perú colonial y más específicamente a la arquitectura y la contaduría de la colonia tardía, y a la historia del mismo Palacio.

PALABRAS CLAVE: Arquitectura, cultura material, terremoto, esclavitud, palacio.

This article is an analysis and transcription of an account book on the rebuilding of the Royal Palace of Lima, after the devastating earthquake of 1746. The document contains detailed information about the origin and costs of the work force and the products used in the rebuilding, information rarely found in documentation from the period. It thus offers a rich entryway into a number of important themes regarding eighteenth-century Peru. These include material culture, the life and death of slaves, and construction techniques. It contributes to the understanding of social and economic history of colonial Peru and more specifically to late colonial architecture and accounting, as well as the history of the Palace itself.

KEYWORDS: Architecture, material culture, earthquake, slavery, palace.

La noche del 28 de octubre de 1746, uno de los más violentos terremotos de la historia virreinal asoló la ciudad de Lima, dejando más de mil muertos y la gran mayoría de edificios dañados. Poco después, y como consecuencia del movimiento sísmico, un maremoto terminó de destruir el Callao, el puerto más importante de América del Sur, pereciendo cerca a 4,000 personas. Tal fue la fuerza de las olas que algunos barcos quedaron varados un kilómetro tierra adentro. Fueron meses aterradores para la capital del virreinato del Perú, ya que las réplicas del sismo continuaron. Desde entonces Lima cambió en varios sentidos. El virrey Manso de Velasco se 
vio en aprietos para auxiliar a los heridos, asegurar el abastecimiento de productos básicos, y evitar saqueos y otros desordenes. También debía preocuparse por "la amenaza interna" de Juan Santos Atahualpa que dirigía una rebelión en la selva central, y por "la externa", ya que los ingleses no dejaban de amenazar a España y sus territorios ultramarinos. Manso de Velasco logró afrontar los daños del terremoto, reedificando gran parte de la ciudad y cambiando así su fisonomía. Por sus esfuerzos recibió el título de conde de Superunda ("sobre las olas"). ${ }^{1}$

Lo que presentamos aquí es la transcripción del "Libro de cargo y data de don Miguel de Echeverria que contiene los gastos de la fabrica y obras del Real Palacio desta ciudad". Es un libro de cargo (ingreso) y data (egreso) del dinero administrado por el encargado de la obra, don Miguel de Echeverría, desde que fue nombrado sobrestante, ${ }^{2}$ para las obras de reconstrucción del Palacio (también conocido como Palacio de Pizarro, de los Virreyes, y de Gobierno), el 28 de septiembre de 1748 hasta el 12 de noviembre de 1751, cuando fue nombrado un nuevo sobrestante. El documento, encuadernado en pergamino y en buen estado de conservación, se encuentra en el Archivo General de la Nación (Lima). ${ }^{3}$

El texto interesa por varias razones. En primer lugar, porque siendo uno de los edificios más emblemáticos de Lima colonial y un centro del quehacer político desde el siglo XVI, el Palacio tiene importancia en sí. No sólo ha sido la residencia de virreyes y presidentes sino que también fue sede en la colonia de la Real Audiencia, la Real Hacienda, la Cárcel Real, y otras instituciones. Sin embargo, a pesar de ser por más de cuatro siglos la residencia del jefe de gobierno, el local de diferentes ramos del estado, y el lugar de importantes actividades protocolares y diplomáticas, no contamos con muchas fuentes publicadas sobre el Palacio. Llama la atención el contraste entre la fascinación causada por la Catedral en los especialis-

1 Para relaciones del terremoto, ver Odriozola, Manuel: Terremotos, Aurelio Alfaro, Lima, 1863. Análisis recientes incluyen Aldana Rivera, Susana: “¿Ocurrencias del tiempo? Fenómenos naturales y sociedad en el Perú colonial”, en García Acosta, Virginia: Historia y desastres en américa latina, vol. 1, CIESAS/La Red, Bogotá, 1996, págs. 167-194; Pérez Mallaína, Pablo Emilio: Retrato de una ciudad en crisis: La sociedad limeña ante el movimiento sísmico de 1746: CSIC, Escuela de Estudios Hispano-Americanos y PUC, Instituto Riva-Agüero, Sevilla, 2001; Walker, Charles: "Shaking the Unstable Empire: the Lima, Quito, and Arequipa Earthquakes, 1746, 1783, and 1797", en Johns, Alessa (ed.): Dreadful Visitations: Confronting Natural Catastrophe in the Age of the Enlightenment, Routledge, New York, 1999, págs. 113-144; y la prometedora investigación en curso de Susy Sánchez.

2 El sobrestante era el encargado de controlar la asistencia de capataces y peones a las obras, de reunirlos en cuadrillas y ordenarles las tareas que debían realizar.

3 El documento forma parte del fondo Libros de Cuentas, legajo: 412, libro: 1831. 
tas de la arquitectura y temas afines y los escasos trabajos sobre el Palacio. Este trabajo puede ayudar a la tarea de escribir la historia del palacio y a llenar este vacío. En segundo lugar, los datos presentados de manera precisa en el texto iluminan muchos aspectos de la vida económica y social de Lima a mediados del siglo XVIII. Contiene información relevante sobre los precios, la producción, los métodos de construcción, la vida (y muerte) de los esclavos, y otros temas que analizaremos más abajo. Es un magnífico cuadro de la cultura material de Lima en el siglo XVIII. Antes de entrar en más detalle sobre su importancia como fuente para la historia de Lima, explicaremos el significado u objetivo del documento mismo.

\section{Las cuentas coloniales y don Miguel de Echeverría}

Conocido en la época como libro manual "particular", en estos se llevaba una cuenta aparte de la cuenta general, en este caso la de una función específica encomendada a don Miguel de Echeverría. La cuenta de Echeverría formaba parte de los egresos de la Caja Real de Lima, y se le había ordenado, para efectos de fiscalización, que “...lleve quenta, y razon de ellos con toda individualidad...". Este libro es donde nuestro funcionario ordenó sus cuentas para presentarlas a sus superiores. Para ejecutar las obras de la reconstrucción del Palacio don Miguel de Echeverría recibía dinero de las arcas de la Real Hacienda, siguiendo un trámite que, como veremos después, era bastante lento. Solicitaba el dinero que necesitaba a la junta de fábrica, un consejo de ministros y oficiales reales para los asuntos de la reconstrucción. Después de analizarlas, la junta las hacía llegar al Superior Gobierno, que por decretos ordenaba a la Caja Real de Lima que le entregaran el dinero. De estos decretos se tomaba razón en el Tribunal Mayor de Cuentas para cuando llegara el momento de fiscalizar sus cuentas. Por cada gasto que realizaba, Echeverría debía recabar boletas y recibos, documentos comprobantes de la cuenta con los que acreditaría sus gastos. Antes de dejar el cargo, reunió y ordenó estos documentos, los resumió en el libro, y los presentó con el libro al Tribunal Mayor de Cuentas.

4 Archivo General de la Nación (AGN), Fondo: Ministerio de Hacienda, Sección: Libros coloniales (H-3), libro: 695, año: 1748, folio 63v. Hay referencias al dinero entregado a Echeverría y a su viuda doña Isabel de Uceda desde 1748 hasta 1752 en Archivo de Indias, Contaduría, Leg. 1771, Cuentas de Real Hacienda, Perú, 1748-1754, "gastos extraordinarios". Debemos esta pista a PérezMallaína, Retrato, quien ha trabajado esta fuente para examinar los gastos en la reconstrucción de Lima. 
El Tribunal Mayor de Cuentas, órgano auditor de la Hacienda virreinal, realizó una auditoría de su administración y función, como correspondía a toda institución o funcionario que administrara parte de la Real Hacienda. Según los procedimientos de este Tribunal, el libro debía ser revisado primero por un contador ordenador, quien ordena y verifica que todos los documentos que Echeverría presentó coincidan con las partidas asentadas en el libro. Efectivamente, en la tapa de pergamino del libro hay una anotación de segunda mano, con caligrafía diferente a la que intitula el libro, que lo declara "Ordenado". Finalmente uno de los contadores de cuentas, en nuestro caso don Simón de Ontañón Jiménez Lobatón, conde de Las Lagunas, visto el informe del anterior y verificándolo personalmente, procede a hacer el "fenecimiento" de la cuenta, la aprobación. ${ }^{5}$

Por cada rubro que reúne varias partidas, Echeverría realizó un sumario de sus cantidades de pesos. Así tenemos uno para las partidas de cargo, y varios para las de data, por ejemplo los adobes, la cal, los ladrillos, etc. Finalmente hace un sumario general de todas las partidas de data y realiza el balance del cargo y la data, del que resultó un saldo a su favor por el dinero que desembolsó "...para que, se continuasen las obras...sin sezar, por causa de no librarseme promptamente las cantidades necessarias,...". Concluye la cuenta con el juramento a Dios y a la Cruz, asegurando que la cuenta es cierta sin dolo ni fraude contra la hacienda del Rey. Finalmente hace dos advertencias en las que da cuenta de los materiales que quedaron a su cargo y entrega al nuevo sobrestante Juan Carrillo, y la otra en que manifiesta las deudas que deja por no haber podido suplir con su propio dinero los que no se le dieron a tiempo en la Caja Real. Estas deudas quedaban pendientes para ser canceladas por la Real Hacienda, así como la que debía satisfacerse, cuando se revisará y aprobará la cuenta, al propio Echeverría, o a sus herederos, por los suplementos que hizo.

Sabemos poco de don Miguel de Echeverría, en parte porque no fue un hombre poderoso de Lima del siglo XVIII, sino otro inmigrante que buscó hacer fortuna en el Perú. Los protocolos notariales nos indican que nació en San Sebastian, provincia de Guipuzcoa, señorío de Vizcaya, hijo legítimo de

5 El texto fundamental sobre las finanzas públicas de la colonia es de Escalona Agüero, Gaspar: Gazofilacio Real del Perú, Editorial del Estado, Biblioteca Boliviana, 2a serie, 1, 4a ed., La Paz, 1941 [1647]. Ver también: Escobedo, Ronald: Control fiscal en el virreinato peruano. El Tribunal de Cuentas, Editorial Alhambra, Madrid, 1986; Merea Llanos, Víctor: "La contabilidad en la colonia", Revista del Archivo General de la Nación, 11, Lima, 1995, págs. 83-104; TePaske, John y Herbert Klein: The Royal Treasuries of the Spanish Empire in America, vol. 1, Peru: Duke University Press, Durham, 1982, págs. vii-xxxx. 
don José de Echeverría y de doña Luisa Analtvitate. Casado con doña Isabel de Uceda, tuvo tres hijos: don Vicente, don Mariano y doña María Echeverría. Poco después de entregar este documento, murió en Lima el 30 de diciembre de 1751. Entre 1748 y fines de 1751, fue contador receptor de derechos del Tribunal del Consulado de Lima, labores que ocupaban su tiempo junto a la reconstrucción del Palacio, además de algunos decomisos de mercaderías de contrabando que realizó en el puerto del Callao. ${ }^{6}$

\section{El Palacio y sus detractores}

En contraste con su vecina en la Plaza de Armas, la Catedral, se ha escrito poco sobre el Palacio en el terremoto y su reconstrucción. La atención prestada a la iglesia mayor se debe en gran parte a su propia belleza y su importancia arquitectónica y simbólica para Lima. Como escribió Francisco Ruiz y Cano para la celebración de la reconstrucción de la Catedral después de 1746, "Quál, pues, de todos los edificios que componían a LIMA, podia con mayor proporción decirle corazón de sus fabricas: que su Iglesia Cathedral?"7 El Palacio no ha suscitado el mismo aprecio. A través de los siglos observadores (cronistas, especialistas en Lima, y viajeros entre otros) lo han descrito en términos ambivalentes o hasta negativos. Pero este contraste entre la fascinación con la Catedral y el comparativo desinterés por el Palacio también puede reflejar, posiblemente, las diferentes formas de plantear o discutir las reformas. Mientras que las constantes modificaciones del Palacio fueron productos de los deseos o visión de casi cada virrey y no fueron materia de discusión, la cuestión de como rehacer la Catedral—si bajar sus torres, buscar nuevos métodos, etc.—causó mucha discusión, produciendo así las fuentes primarias empleadas por los histo-

6 AGN, Fondo: Protocolos Notariales siglo XVIII, escribano Pedro Espino Alvarado, protocolo N. ${ }^{\circ}$ 282, año 1730, folio 1849-1850v; y escribano Juan Bautista Tenorio Palacios, protocolo N. ${ }^{\circ}$ 1001, Año: 1749-1750, Folios 1007v-1009. Sobre el decomiso de contrabando, AGN, H-3, libro: 704, año: 1749 , folio: $2 \mathrm{v}$.

7 Ruiz Cano y Galiano, Francisco Antonio: Jubilos de Lima en Dedicación de su Santa Iglesia Cathedral..., Calle del Palacio, Lima, 1755, págs. 2-3.

8 Tenemos una amplia bibliografía sobre la reconstrucción de la Catedral. Aparte del legajo entero dedicado a ello en el Archivo General de Indias, (Audiencia de Lima, Leg. 511), se puede consultar Bernales Ballesteros, Jorge: Edificación de la Iglesia Catedral de Lima (Notas para su historia), Universidad de Sevilla, Sevilla, 1969; San Cristóbal, Antonio: La Catedral de Lima: Estudios y Documentos: Museo de Arte Religioso de la Catedral de Lima, Lima, 1996; García Irigoyen, Manuel: Historia de la catedral de Lima, El País, Lima, 1898; Pérez-Mallaína, Retrato, págs. 151-170. 
riadores. ${ }^{8}$ Es una hipótesis difícil de sostener pero consta que la Catedral ha sido tema de muchos más estudios que el Palacio.

Las relaciones conocidas sobre el terremoto dan información general y repetitiva de los daños que sufrió el Palacio. "La individual y verdadera relación de la extrema ruina...", obra anónima con ediciones en varios idiomas, declara que "El Palacio del Excmo. Señor Virrey en donde se encierran las salas de la Real Audiencia, el Tribunal de Cuentas, Caja Real, y demas oficios de la dependencia del Gobierno, han quedado sin habitacion ni oficina capaz de subsistir". ${ }^{9}$ Un erudito observador de la catástrofe, José Eusebio de Llano y Zapata, se refiere a la destrucción de "dos Palacios que miran a la plaza mayor, una habitacion de los Señores Virreyes, donde están la Real Audiencia, Sala del Crimen, Tribunal de Cuentas, Caja Real, Sala de Armas, y los Almacenes, en que se guardan pólvora, artillería, granada, fusiles, y demas pertrechos de guerra ....". ${ }^{10}$ Victorino Montero del Aguila menciona los arreglos provisionales anteriores a las obras de Echeverría: "El dia 23 de Enero, se abrieron los Tribunales de Justicia, reparadas las Reales Salas de Audiencia con robustos telares de madera, que no dexan rezelo a mayores Temblores, que las muevan". Meses después, en junio 1747, el Virrey abandona "sus barracas en la Plaza mayor" y regresa al Palacio. ${ }^{11}$ En su relación de gobierno, el Virrey hace alarde de su estadía en la plaza mayor. ${ }^{12}$

El terremoto de 1746 no fue el primero ni el último desastre natural que afectó el Palacio. Más bien, fue sujeto, o tal vez víctima, de constantes renovaciones debido a los incendios y sismos que padeció. Se puede entonces resumir una buena parte de su historia a través de los desastres "naturales". Pizarro lo ubicó sobre el palacio de Taulichusco, el curaca del valle del Rímac, cuando fundó la ciudad en 1535, aunque no lo vio terminado al ser asesinado en 1541. Un terremoto arruinó el edificio original en 1586, mientras que los sismos de 1687 y el que obligó la reconstrucción de

9 Odriozola, Terremotos, pág. 153.

10 Llano Zapata, José Eusebio de: Observación Diaria Crítica-Histórica-Meteorológica”, en Odriozola, Terremotos, pág. 138.

11 Montero del Aguila, Victorino: Noticia Annalica y Estado, que Tiene el Puerto del Callao, y la ciudad de Lima, a el Año Cumplido de su Desolación y Ruina, que lo hace ene este mes de Octubre de 1747, Lima, 1747, pág. 4. Sobre este autor, ver: Lohmann Villena, Guillermo: "Victorino Montero del Aguila y su 'Estado Político del Reyno del Perú' (1742)”, Anuario de Estudios Americanos, XXXI, Sevilla, 1973, págs. 751-807.

12 Conde de Superunda, Relación de gobierno, Perú (1745-1761), edición de Alfredo Moreno Cebrián, CSIC, Madrid, 1983, págs. 260-261.

13 Cantuarias, Ricardo A.: "El Palacio de Gobierno del Siglo XVI al XX", Nueva Síntesis, 1-2, Lima, 1994, págs. 78-80; Pastor, Martín: De la vieja casa de Pizarro al nuevo Palacio de Gobierno, Imprenta Torres Aguirre, Lima, 1938, págs. 311-314. 
Echeverría, el de 1746, causaron grandes daños. ${ }^{13}$ Es víctima de por lo menos dos incendios en el siglo XVII, y en 1804 se quemó uno de los "cajones" o tiendas del frente del Palacio, llegando a incendiarse el archivo del Tribunal Mayor de Cuentas. En la reconstrucción, no se permitieron más "cajones de ribera". ${ }^{14}$ El Palacio sufrió otro incendio en 1923 que obligó la construcción de un nuevo edificio, el actual, terminado en 1938.15

Aunque algunos escritores como Cobo tienen palabras halagadoras para el Palacio, otros enfatizan las constantes obras que lo afectan, los cajones o tiendas en su frente que lo afean, y su poca presencia frente a los otros edificios que conforman la Plaza Mayor. Cobo la llama "la mayor y más suntuosa casa de este reino, por su gran sitio por lo mucho que todos los virreyes han ido ilustrándola con nuevos y costosos edificios, porque apenas ha habido virrey que no la haya acrecentado con algún cuarto o pieza insigne..." ${ }^{16}$ Gregorio Cangas (1770) justifica el hecho de que no sea muy elevado por la constante amenaza de los terremotos e insiste que el edificio es más grande de lo que parece desde afuera. En su "Descripción en diálogo de la ciudad de Lima entre un peruano práctico y un bisoño chapetón", el "peruano" explica al "chapetón":

que aunque lo bajo de la fachada de este palacio por estar construido en un solo terraplén, representa ser pequeño, no lo es, y es engaño que causa su construcción la que se hizo en esta disposición por el recelo de los muchos continuados temblores y terremotos, que fue siempre de considerable elevación pero no obstante no deja de ser espacioso porque dentro se halla el despacho y sala de todos los tribunales. ${ }^{17}$

Un autor anónimo de la misma época es contundente al escribir “...el Palacio del Virrey, que no teniendo nada de magnífico sólo merece el nom-

14 Cantuarias, "El Palacio", pág. 87. Para una relación breve y deprimente sobre la pérdida de la documentación de los archivos del Palacio, ver Silva Santisteban, Fernando: "Algunos archivos históricos y repositorios de Lima”, Fénix, 12, Lima, 1955, págs. 145-182; y Lohmann Villena, Guillermo: "Los fondos del Archivo General de la Nación y su valor para la investigación", Revista del Archivo General de la Nación, 21, Lima, 2000, págs. 137-156.

15 Pastor, De la vieja casa, pág. 188.

16 Cobo, citado en Huertas, Lorenzo V.: "Introducción al estudio de la Plaza Mayor de Lima", Historia y Cultura, 23, Lima, 1999, pág. 299.

17 Cangas, Gregorio de: Descripción en diálogo de la ciudad de Lima entre un peruano práctico y un bisoño chapetón, Vicente, Camilo G. y José L. Lenci, eds. BCR, Lima, 1997, págs. 25-26.

18 Duviols, Jean-Paul: Descripción de la ciudad de Lima Capital del Reyno....,, en Thiercelin, Raquel (ed.): Cultures et sociétés Andes et Méso-Amérique. Mélanges en hommage a Pierre Duviols, Université de Provence, Provence, 1991, vol. 1, pág. 258. El texto, la transcripción de un documento de la Biblioteca Nacional de Madrid, es una excelente referencia en cuanto a la arquitectura de la época del terremoto y la reconstrucción del Palacio. 
bre por la persona que lo habita". ${ }^{18}$ En 1860, Ephrain Squier resume esta ambivalencia, llamando al edificio una "aglomeración confusa, intrincada y heterogénea de desproporcionados cuartos, salones y gabinetes de todas las formas y eras, que constituyen un verdadero laberinto" a la vez que resalta su importancia histórica, enumerando los gobernadores (3), virreyes (43) y jefes de estado (150) que lo tuvieron como residencia. ${ }^{19}$ Esta ambivalencia, reflejo de la mayor grandeza de otros edificios, particularmente iglesias y conventos, y tal vez de un cierto escepticismo de la población frente a los gobernantes, contribuye a la escasa atención prestada al Palacio por parte de los historiadores y arquitectos. Este documento puede ayudar a la tarea de escribir la historia del Palacio.

\section{Reconstruyendo el Palacio}

Más allá de su contribución a la historia de la Plaza de Armas y del Palacio mismo, el documento es una importante fuente sobre la cultura material en la colonia. ${ }^{20}$ La descripción detallada de los gastos da una idea clara sobre la procedencia y el costo de los materiales y las diferentes categorías de trabajadores. En el cuadro 1, se dividen los gastos en cinco rubros: mano de obra, materiales, transporte, esclavitud, y menudencias. Obviamente, no son categorías excluyentes entre si. Por ejemplo, en algunos casos el cobro del material incluía el costo de su flete. Vemos, sin embargo, algunas tendencias. El gasto mayor fue en mano de obra (58\%) mientras que los materiales constituyeron el segundo rubro (26\%). El tercero consistió de "menudencias" no detalladas (8\%), y el transporte y desmonte constituyeron el cuarto, (6\%). En cuanto a la esclavitud, se gastó menos de dos por ciento del total. Es importante notar que estos gastos no incluyeron la compra de los esclavos mismos ni sus alimentos sino solamente el costo de otros aspectos claves de su "mantenimiento": ropa y frazadas, implementos para la cocina, bautismo, enseñanza de la doctrina cristiana, curación, y entierros. Constituye una resumida lista de las necesidades básicas de un sistema esclavista cristiano.

19 Citado en Huertas, "Introducción”, pág. 319.

20 Para un espléndido análisis de la cultura material de América Latina, ver Bauer, Arnold: Goods, Power, History. Latin America's Material Culture, Cambridge University Press, Cambridge, 2001, de próxima aparición en español. 
Nos recuerda la necesidad de diferenciar la esclavitud de otras formas de trabajo. Por un lado se constituye de gastos no cubiertos normalmente en sistemas más "libres", como la preparación de la comida, la vestimenta, y las frazadas. También vemos el lado más oscuro: la muerte de estos trabajadores, según indica el gasto en "los entierros de seis negros bozales esclavos de $\mathrm{Su}$ Majestad que murieron y se enterraron en el Hospital de San Bartholome". Estas muertes nos dan una idea de la dureza del trabajo y el trato. La cita también explica su procedencia: eran esclavos del Rey o del Estado a cargo del virrey. Un verdadero análisis de su costo tendría que tomar en cuenta el precio pagado por los esclavos. Al respecto, contamos con un dato parcial sobre la compra de estos esclavos. El 17 de setiembre de 1748 los oficiales de la Caja Real de Lima entregaron a Antonio de Orejuela, maestre de la fragata "San Francisco de Paula", próxima a partir a Panamá conduciendo el situado, 10,000 pesos para comprar esclavos para las obras del Palacio. ${ }^{21}$ No hemos podido confirmar si se gastó todo el dinero ni cuantos esclavos se compraron, lo cierto es que se adquirieron expresamente para las obras del Palacio. Por otra parte, en el libro de Echeverría no se especifican los gastos de alimentación de los esclavos, pero parte del dinero que se le entregaba en la Caja Real era para la "...manutenzion de los negros". ${ }^{22}$

En cuanto a los materiales, los adobes, la cal, los ladrillos, y la madera son los más importantes y constituyen casi la cuarta parte del gasto total de la obra. Se compran 157,000 adobes, 57,500 de ellos hechos en el Palacio con los desmontes, sistema práctico y hasta ecológico. De estos, los del primer piso eran más baratos que los del segundo piso debido a la relativa facilidad de trabajo. Se usan más de 100,000 ladrillos, 5,070 fanegas de cal, 535 libras de clavos ("clabazón"), y una variedad de piedras distinguidas por su procedencia y uso: de Callao, de cerro, de río, de losa, de sillería y de empedrar. ${ }^{23}$ Estas cantidades demuestran que fue una obra

21 AGN, H-3, libro: 695, año 1748, folio: 162.

22 AGN, H-3, libro: 709, año 1750, folios: 163v y 169v.

23 El texto imprescindible sobre las materiales en las construcciones coloniales, y su arquitectura en general, es Harth-Terré, Emilio y Alberto Marqués Abanto: "Las Bellas Artes en el virreynato del Perú. Historia de la casa urbana virreynal de Lima", Revista del Archivo Nacional del Perú, XXVI, 1, Lima, 1962, págs. 109-206, sobre todo 164-186.

24 Para el debate sobre el comercio con Chile en el siglo XVIII, ver entre otros Flores Galindo, Alberto: Aristocracia y plebe: Lima, 1760-1830: Mosca Azul, Lima, 1984, págs. 54-84; PérezMallaína, Pablo Emilio: "La fabricación de un mito: el terremoto de 1687 y la ruina de los cultivos de trigo en el Perú", Anuario de Estudios Americanos, LVII-1, Sevilla, 2000, págs. 69-88; Ramos Pérez, Demetrio: Trigo chileno, navieros del Callao y hacendados limeños entre la crisis agrícola del siglo xvii y la comercial de la primera mitad del XVIII, CSIC, Instituto Gonzalo Fernández de Oviedo, Madrid, 1967. 
grande, una reconstrucción en vez de refacción. En la lista de materiales se hace presente el importante comercio con Chile ya que se refiere a tablas de "Chilué" y cueros de novillos de Chile. ${ }^{24}$ Normalmente no especifica la procedencia de productos más locales, aunque sí se refiere a las caleras de los padres betlemitas y agustinos.

El documento no sólo da luces sobre los productos sino también sobre quienes hacían los diferentes trabajos. Como se ve en el cuadro 1 y en el índice del mismo documento la lista incluye los siguientes artesanos: albañiles, aserradores, canteros, carpinteros, empedradores, herreros, hojalateros, pintores y torneros. Don Salvador Ubaldo de Castro, teniente de cura de la Catedral, firmó el recibo de 48 pesos por bautizar a veinticuatro "negros bozales esclavos" mientras que el padre dominico fray Juan de Valenzuela se encargó de la enseñanza de "la doctrina christiana, y catetissar a los negros bozales esclavos de Su Majestad". Tuvo a su cargo veintiún individuos. Como mencionamos, seis esclavos murieron mientras que uno, Cristóbal, pasó veintinueve días en el Hospital de Espíritu Santo. Es curioso que fuera internado en este, designado para "gente de mar", en vez del Hospital de San Bartolomé, "de negros y mulatos de ambos sexos" y donde murieron los seis esclavos mencionados. Su convalecencia ahí puede explicarse por los fuertes daños que sufrió el Hospital de San Bartolomé y por la cercanía de Hospital de Espíritu Santo a la Plaza de Armas. ${ }^{25}$

Los jornaleros representaron el gasto mayor en las obras. De ellos, no tenemos nombres ni procedencia sino meras cifras ${ }^{26}$ Cristóbal de Vargas, maestro alarife de albañilería, recibió 7,536 pesos y 2 reales, de los cuales 1,580 le correspondieron por su sueldo (10 pesos semanales por 158 semanas). De esta suma tuvo que pagar a los "demas oficiales mayores y menores de este arte". Los otros maestros también pagaron a sus artesanos y jornaleros. El maestro carpintero Pedro de los Reyes recibió 18,932, y 6 reales para su salario y de sus diferentes trabajadores. Dentro del rubro "Peones Jornaleros" se pagó 15,907 pesos y 2 reales "a diferentes peones jornaleros, que trabajaron, en las obras del Real Palacio...a razon de a seis reales menos los barreros a quienes se les pagaron a 8 reales...". Esta cifra cubriría aproximadamente 30 jornaleros a 6 reales al dia. Aunque la cifra es

25 Conde de Superunda, Relación, pág. 215. Para la lentitud de la reconstrucción del Hospital San Bartolomé, ver Cahill, David: "Financing Health Care in the Viceroyalty of Peru: The Hospitals of Lima in the Late Colonial Period", The Americas, 52, Washington D.C., 1996, págs. 135-37.

26 Sobre clases populares en Lima del XVIII, la consulta indispensable es Flores Galindo, Aristocracia. 
inexacta, nos da una idea de la intensidad de la obra. El documento no menciona si entre estos peones se contaban trabajadores forzados como los había en la contemporánea construcción de la fortaleza del Callao. Por otra parte, los gastos consignados en el libro de Echeverría no fueron los únicos que se hicieron en la reconstrucción del Palacio. Por ejemplo, algunos parecen haber estado al cuidado del Juan Bautista de Casabona, mayordomo pardo del virrey Manso de Velasco, a quien en setiembre de 1748 se le reintegraron los pesos que gastó en "... la composicion de la cañeria de este Real Palacio.” y “...de la Real Capilla de este Palacio, en las zelebridades, luminarias y otros gastos nezesarios...". ${ }^{27}$

Hemos presentado algunos aspectos interesantes del documento y esperamos que los lectores encuentren otros. Los historiadores económicos pueden aprovechar bien las cifras sobre los precios de los productos, el transporte, y la mano de obra. Por otro lado, no nos parece descabellado un análisis literario o discursivo de este tipo de documento, tan común en los archivos históricos hispanoamericanos. Su organización y lenguaje iluminan la mentalidad contable de entonces. Los arquitectos podrían usar la información para dar una idea clara de las técnicas en esta época, la del ocaso del barroco peruano. Uno de los motivos de transcribir y publicar este documento es la variedad de uso o lecturas que pueda tener.

Para los especialistas en el periodo colonial, el documento resultará de lectura fácil. Pero los no especialistas también podrán entenderlo. La transcripción se realizó siguiendo las "Normas para la transcripción de documentos históricos hispanoamericanos", aprobadas en la Primera Reunión Interamericana sobre Archivos, en Washington, el 27 de octubre de 1961. En la transcripción se conserva el valor fonético y literal de las letras. Las letras $c ̧, c, s, s s, b, u$ y $v$ se han transcrito como aparecen en el documento, manteniendo la ortografía original. Se han respetado la puntuación y las contracciones originales, y se han desarrollado las abreviaturas. Por lo tanto, se pueden generar algunas confusiones entre la ortografía actual, basada en reglas, y la de esa época, prácticamente sin reglas y que solo se ajustaba al criterio de quien escribía. Con un poco de paciencia, se entiende perfectamente. En cuanto al aspecto cuantitativo, el sistema es simple. Son pesos de 8 reales así que el jornalero que gana 6 reales al dia gana 3 pesos y 6 reales a la semana $(6 \times 5=30$, dividido entre ocho $=3,6 / 8)$.

27 AGN, H-3, libro: 695, año 1748, folio: 161 y 161v. 



\section{Transcripción paleográfica*}

"Libro de cargo y data de don Miguel de Echeverria que contiene los gastos de la fabrica y obras del real palacio desta ciudad. ${ }^{28}$

\section{[Crismón]}

Libro de cargo y data de don Miguel de Echeverria que contiene los gastos de la fabrica y obras del real palacio desta ciudad.

\section{[Crismón]}

Libro que [roto: yo] don Miguel de Echeverria, sobrestante nombrado, para la costrucion y fabrica, de las obras del real palacio de esta ciudad de Lima, formo de las cantidades de plata que boy reciviendo por decretos del Superior Govierno, y assimismo de [roto: todas] las porciones que se gastan en las expresadas obras, materiales, alarifes, peones, y todo lo demas conserniente, segun la variedad de que se componen.

\section{YNDICE}

\section{Cargo Data}

Cargo de plata a folio 1 Maestro alarife, de albañileria, y oficiales. a folio 7.

Adobes y su paga.

a folio 8 .

Paga de piedra de silleria, su conducion, y canteros. a folio 9 .

Paga de cal.

a folio 10 .

Paga de ladrillos, de solar, y de labrar.

a folio 11 .

Paga de requas de polvo.

a folio 12 .

Paga de requas de arena.

a folio 13 .

Paga de piedras.

a folio 14

Paga de paxa.

a folio 16 .

Paga de yesso.

a folio 17 .

Tazassion de desmontes.

a folio 18 .

Paga de desmontes.

a folio 19 .

Conducion de cañones.

a folio 20

Paga de un perol.

a folio 21 .

Paga de erramientas.

a folio 22 .

Paga de clabazon.

a folio 23 .

Paga de erreria.

* Archivo General de la Nación. Fondo: Libros de Cuentas. Legajo: 412. Libro: 1831. Año: 1748-1751. 
Paga de jornales.

a folio 25 .

Paga de carpinteros.

a folio 26 .

Madera comprada.

a folio 27 .

Conducion de madera.

a folio 28 .

Paga de azerradores.

a folio 29 .

Paga de torneo de balaustres.

a folio 30 .

Paga de caña braba.

a folio 31 .

Compra, y conducion de tablas.

a folio 32 .

Paga de ropa de la tierra, para bestir los negros.

a folio 33 .

Paga de frezadas, y ponchos.

a folio 34 .

Paga de baptismos de los negros.

a folio 35 .

Paga de la enzeñanza de la doctrina christiana.

a folio 36 .

Paga por los entierros de los negros muertos.

a folio 37 .

Paga de curacion de negros.

Paga de empedradores.

a folio 38 .

Paga al ojalatero.

a folio 39 .

Paga de cueros comprados.

a folio 40 .

Paga de las pinturas.

a folio 41 .

Ymporte de la memoria jurada.

a folio 42 .

a folio 43 .

Advertencias.

a folio 45 .

\section{[Crismón]}

Cargo de las cantidades de plata que yo don Miguel de Cheveria, sobrestante nombrado para las obras de la fábrica del real palacio de esta ciudad de Lima boy reciviendo de los oficiales reales de ella en virtud de decretos de este Superior Govierno, desde el día veinte y ocho de septiembre, de mil setecientos quarenta y ocho, en adelante, para efecto de costear las dichas obras.

En veinte y ocho de septiembre de mil setecientos quarenta y ocho años, me hago cargo, de dos mil pesos de a ocho, que por decreto de este dia, libro el Superior Govierno, para empesar a costear las obras de la fabrica del real palacio de esta ciudad, en cuya virtud me los entregaron los oficiales reales de ella, de que di carta de pago.

2,000 ps.0.

Miguel de Echeverria [Rubricado]

En ocho de noviembre de mil setecientos quarenta y ocho años, me hago cargo de dos mil pesos que assimismo me entregaron los oficiales reales, en virtud de decreto del Superior Govierno, de este dia, para el referido efecto, de que di carta de pago.

Miguel de Echeverria [Rubricado]

En primero de febrero de mil setecientos quarenta y nuebe años, me hago cargo de quatro mil pesos, que por decreto de este dia me entregaron los oficiales reales, para el mis- 
mo efecto, de continuar las dichas obras, de que di carta de pago.

Miguel de Echeverria [Rubricado]

4,000 ps.0.

En catorze de abril de mil setecientos quarenta y nuebe años, me hago cargo de tres mil pesos, que por decreto del Superior Govierno me entregaron los dichos oficiales reales, para el mismo efecto de que di carta de pago.

Miguel de Echeverria [Rubricado]

En treze de mayo de mil setecientos quarenta y nuebe años, me hago cargo de dos mil pessos, que en virtud de decreto del Superior Govierno me entregaron los dichos oficiales reales, para el expressado efecto de que di carta de pago.

\section{Miguel de Echeverria [Rubricado]}

$2,000.0$.

En siete de julio de mil setecientos quarenta y nuebe años, me hago cargo de dos mil pessos que por decreto del Superior Govierno me entregaron los oficiales reales de que di carta de pago.

\section{Miguel de Echeverria [Rubricado]}

$3,000.0$

En treze de agosto de mil setecientos quarenta y nuebe, me hago cargo de dos mil pesos que en virtud de decreto del Superior Govierno me entregaron dichos oficiales reales de que di carta de pago.

\section{Miguel de Echeverria [Rubricado]}

En veinte y siete de septiembre de mil setecientos quarenta y nuebe, me hago cargo de tres mil pesos que por decreto del Superior Govierno me entregaron los oficiales reales de que di carta de pago.

\section{Miguel de Echeverria [Rubricado]}

En veinte y ocho de noviembre, de mil setecientos quarenta y nuebe, me hago cargo de dos mil pesos que por decreto del Superior Govierno me entregaron dichos oficiales reales de que di carta de pago.

\section{Miguel de Echeverria [Rubricado]}

En quatro de diciembre de mil setecientos quarenta y nuebe, me hago cargo de tres mil pessos, que en virtud de decreto del Superior Govierno me entregaron los oficiales reales de que di carta de pago.

\section{Miguel de Echeverria [Rubricado]}

En tres de enero de mil setecientos çinquenta años, me hago cargo de tres mil pesos, que por decreto del Superior 
Govierno me entregaron los oficiales reales de que di carta de pago.

Miguel de Echeverria [Rubricado]

3,000.0.

En quatro de febrero de mil setecientos y çinquenta, me hago cargo de quatro mil pesos, que en virtud de decreto del Superior Govierno me entregaron los oficiales reales de que di carta de pago.

Miguel de Echeverria [Rubricado]

4,000.0.

En treze de marzo de mil setecientos y çinquenta años, me hago cargo de dos mil pesos, que en virtud de decreto me entregaron los oficiales reales de que di carta de pago.

Miguel de Echeverria [Rubricado]

En diez y ocho de marzo de mil setecientos y cinquenta, me hago cargo de tres mil pesos, que por decreto me entregaron los oficiales reales de que di carta de pago.

Miguel de Echeverria [Rubricado]

En onze de abril de mil setecientos y cinquenta, me hago cargo de dos mil pesos, que en virtud de decreto me entregaron los oficiales reales de que di carta de pago.

Miguel de Echeverria [Rubricado]

En veinte de abril de mil setecientos y cinquenta, me hago cargo de tres mil pesos, que en virtud de decreto me entregaron los oficiales reales de que di carta de pago.

Miguel de Echeverria [Rubricado]

En veinte y nuebe de mayo de mil setecientos y cinquenta, me hago cargo de dos mil pesos, que en virtud de decreto me entregaron los oficiales reales de que di carta de pago.

Miguel de Echeverria [Rubricado]

En veinte y seis de junio de mil setecientos y cinquenta, me hago cargo de dos mil pesos que en virtud de decreto me entregaron los oficiales reales de que di carta de pago.

Miguel de Echeverria [Rubricado]

$2,000.0$

3,000 ps.0.

$3,000.0$.

$2,000.0$

En veinte y siete de julio de mil setecientos y cinquenta, me hago cargo de dos mil pesos, que por decreto del Superior Govierno me entregaron los oficiales reales de que di carta de pago.

Miguel de Echeverria [Rubricado]

En veinte y uno de agosto de mil setecientos y cinquenta, me hago cargo de dos mil pessos, que en virtud de decreto me entregaron los oficiales reales de que di carta de pago.

Miguel de Echeverria [Rubricado] 
En veinte y tres ${ }^{1}$ de setecientos y cinquenta, me hago cargo de dos mil pessos, que en virtud de decreto me entregaron los oficiales reales de que di carta de pago.

Miguel de Echeverria [Rubricado]

En veinte y tres de septiembre de mil setecientos y cinquenta, me hago cargo de trescientos sessenta y cinco pessos seis reales, que en virtud de decreto, me entregaron los oficiales reales de que di carta de pago.

Miguel de Echeverria [Rubricado]

En diez y nuebe de octubre de mil setecientos y cinquenta, me hago cargo de dos mil pessos, que en virtud de decreto me entregaron los oficiales reales de que di carta de pago.

Miguel de Echeverria [Rubricado]

En diez de noviembre de mil setecientos y cinquenta, me hago cargo, de dos mil pessos, que en virtud de decreto, me entregaron los oficiales reales de que di carta de pago. Miguel de Echeverria [Rubricado]

En veinte y ocho de noviembre de mil setecientos y cinquenta, me hago cargo de dos mil pessos, que en virtud de decreto me entregaron los oficiales reales de que di carta de pago.

Miguel de Echeverria [Rubricado]

$2,000.0$.

365 ps.6.

$2,000.0$

$2,000.0$

$2,000.0$

En diez y ocho de diciembre de mil setecientos y cinquenta, me hago cargo de dos mil pesos, que en virtud de decreto me entregaron los oficiales reales de que di carta de pago.

Miguel de Echeverria [Rubricado]

En veinte y cinco de enero de mil setecientos cinquenta y uno, me hago cargo de dos mil pesos, que en virtud de decreto me entregaron los oficiales reales de que di carta de pago.

Miguel de Echeverria [Rubricado]

En veinte y cinco de febrero de mil setecientos, çinquenta y uno, me hago cargo de dos mil pesos, que en virtud de decreto me entregaron los oficiales reales de que di carta de pago.

\section{Miguel de Echeverria [Rubricado]}

En diez y siete de marzo de mil setecientos cinquenta y un años, me hago cargo de dos mil pesos, que en virtud de decreto, me entregaron los oficiales reales de que di carta de pago.

Miguel de Echeverria [Rubricado]

1 No está registrado el mes de esta partida. En los libros de la Caja Real de Lima este egreso está registrado el 23 de septiembre de 1750 . 
En catorze de abril de mil setecientos çinquenta y uno, me hago cargo de dos mil pesos que en virtud de decreto, me entregaron los oficiales reales de que di carta de pago.

Miguel de Echeverria [Rubricado]

En quatro de mayo de mil setecientos cinquenta y uno, me hago cargo de dos mil pesos que en virtud de decreto, me entregaron los oficiales reales de que di carta de pago.

Miguel de Echeverria [Rubricado]

En veinte y dos de mayo de mil setecientos cinquenta y uno, me hago cargo, de quatro cientos y ochenta pesos, que en virtud de decreto me entregaron los oficiales reales de que di carta de pago.

Miguel de Echeverria [Rubricado]

2,000 ps.0.

$2,000.0$

480.0 .

En veinte y siete de mayo, de mil setecientos cinquenta y uno, me hago cargo de quinientos ochenta y un pesos, y dos reales que en virtud de decreto me entregaron los oficiales reales de que di carta de pago.

Miguel de Echeverria [Rubricado]

En veinte y nuebe de mayo, de mil setecientos cinquenta y uno, me hago cargo de dos mil pesos que en virtud de decreto me entregaron los oficiales reales de que di carta de pago.

\section{Miguel de Echeverria [Rubricado]}

\section{2}

2,000 ps.0.

En cinco de julio de mil setecientos çinquenta y uno, me hago cargo de dos mil pesos que en virtud de decreto me entregaron los oficiales reales de que di carta de pago.

Miguel de Echeverria [Rubricado]

En ocho de julio de mil setecientos cinquenta y uno, me hago cargo de novecientos sesenta y dos pessos, y quatro reales que en virtud de decreto me entregaron los oficiales reales de que di carta de pago.

Miguel de Echeverria [Rubricado]

En dos de agosto de mil cetecientos cinquenta y un años, me hago cargo de dos mil pesos que en virtud de decreto me entregaron los oficiales reales de que di carta de pago.

Miguel de Echeverria [Rubricado]

En nuebe de septiembre de mil setecientos cinquenta y uno, me hago cargo de un mil pesos que en virtud de decreto me entregaron los oficiales reales de que di carta de pago.

Miguel de Echeverria [Rubricado]

962.4.

$2,000.0$

1,000. ps.0. 
Sumario de todas las partidas de cargo que contiene este libro.

\begin{tabular}{ccccc}
$2,000 \mathrm{ps} .0$. & $3,000 \mathrm{ps}$. & $2,000 \mathrm{ps}$. & $2,000 \mathrm{ps}$. & \\
$2,000 \mathrm{ps}$. & $4,000 \mathrm{ps}$. & $365 \mathrm{ps} .6$ & $480 \mathrm{ps}$. & \\
$4,000 \mathrm{ps}$. & $2,000 \mathrm{ps}$. & $2,000 \mathrm{ps}$. & $581 \mathrm{ps} .2$ & Sumas Mayores \\
\cline { 5 - 6 } $3,000 \mathrm{ps}$. & $3,000 \mathrm{ps}$. & $2,000 \mathrm{ps}$. & $2,000 \mathrm{ps}$. & $25,000 \mathrm{ps}$. \\
$2,000 \mathrm{ps}$. & $2,000 \mathrm{ps}$. & $2,000 \mathrm{ps}$. & $2,000 \mathrm{ps}$. & $25,000 \mathrm{ps}$. \\
$2,000 \mathrm{ps}$. & $3,000 \mathrm{ps}$. & $2,000 \mathrm{ps}$. & $962 \mathrm{ps} .4$ & $18,365 \mathrm{ps} .6$. \\
$2,000 \mathrm{ps}$. & $2,000 \mathrm{ps}$. & $2,000 \mathrm{ps}$. & $2,000 \mathrm{ps}$. & $11,023 \mathrm{ps} .6$. \\
$3,000 \mathrm{ps}$. & $2,000 \mathrm{ps}$. & $2,000 \mathrm{ps}$. & $1,000 \mathrm{ps}$. & $79,389 \mathrm{ps} .4 \mathrm{rs}$. \\
$2,000 \mathrm{ps}$. & $2,000 \mathrm{ps}$. & $2,000 \mathrm{ps}$. & & \\
$3,000 \mathrm{ps}$. & $2,000 \mathrm{ps}$. & $2,000 \mathrm{ps}$. & & \\
\hline $25,000 \mathrm{ps}$. & $25,000 \mathrm{ps}$. & $18,365 \mathrm{ps} .6$. & $11,023 \mathrm{ps} .6$. &
\end{tabular}

Ymportan todas las partidas de cargo de plata que he recivido, setenta y nuebe mil trescientos ochenta y nuebe pesos quatro reales de a ocho, como parece del sumario de arriba y lo comprueba la certificacion de los oficiales reales de la Caja de esta ciudad, que va por recado justificante del referido cargo.

[Rúbrica de Miguel de Echeverría]

\section{[Crismón]}

Data de las cantidades de pessos que se distribuyen en el sueldo del maestro alarife de albañileria y demas oficiales mayores, y menores de este arte, desde el dia veinte y seis de septiembre, de mil setecientos quarenta y ocho, inclusive en adelante.

Desde el dia veinte y seis de septiembre de mil setecientos quarenta y ocho, hasta el dia dos de octubre de mil setecientos cinquenta y uno inclusive uno y otro da en data siete mil quinientos treinta y seis pessos y dos reales de a ocho, que se pagaron al maestro alarife de albañileria don Cristoval de Vargas, a razon de dos pesos por dia, de sueldo, como a director de la fabrica, y demas oficiales mayores y menores, de la misma facultad, segun lo que a cada [entre líneas: uno] se le asigno por dicho maestro en mas o menos suficiencia de su oficio, como consta de ciento cinquenta y ocho semanas que han mediado en el citado tiempo, y de otros tantos recivos y voletas firmadas del expressado maestro don Cristoval, que van por recados de esta partida, como suficientes para instruirla, en virtud de estar assi mandado por decreto del Superior Govierno, de siete de noviembre de mil setecientos quarenta y ocho, 7,536 ps.2. cuyo testimonio se pone tambien por recado.

Miguel de Echeverria [Rubricado] 
Data de las cantidades de plata que se distribuyen en el precio de los adobes que entraron en la fabrica del real palacio, assi los que se compraron fabricados fuera como los que se mandaron hacer en el mismo palacio por quenta de Su Majestad.

Adobes Desde el dia quince de marzo, de mil setecientos quarenta y nuebe, hasta veinte y quatro de enero, de mil setecientos cinquenta y uno, inclusive uno y otro, se le pagaron a Clemente de Acosta, dos mil novecientos ochenta y un pesos y seis reales por el valor de noventa y nuebe mil y quinientos adobes, que en el citado tiempo hecho con sus requas y de su quenta, para las obras del real palacio de esta ciudad, a razon de treinta pesos cada millar como se hizo el concierto, y lo aprobó el Superior Gobierno, por decreto de siete de noviembre de mil setecientos quarenta y ocho y las dichas cantidades de plata, y expecie expressada constan de quarenta recivos del dicho Clemente de Acosta y voletas del maestro alarife de albañileria don Cristoval de Vargas que van por recados de esta partida, con el citado decreto, en cuya virtud se dan en data los dichos pessos.

2,981 ps.6.

Miguel de Echeverria [Rubricado]

Ydem Assimismo, se dan en data, ochocientos setenta y // ocho pessos, por el valor de cinquenta, y siete mil y quinientos adobes, que se fabricaron dentro de los patios, y techos del real palacio, con las tierras de sus desmontes, por varios peones que los hicieron, los veinte y un mil, a razon de catorze pessos millar, por haverse hecho en el suelo, que importan dos cientos nobenta y quatro pesos y los treinta y seis mil y quinientos en los techos a razon de diez y seis pessos, por haver sido mas pessado el trabajo de fabricarlos, que importaron quinientos ochenta y quatro pessos, y ambas cantidades hacen, la primera expressada de ochocientos ochenta y ocho pesos como todo consta de diez y siete voletas del maestro alarife de albañileria don Cristoval de Vargas, que van por recados de esta partida.

Miguel de Echeverria [Rubricado]

Sumario de las partidas de adobes y plata

\begin{tabular}{ccc} 
Adobes & Plata \\
\hline $99,500$. & $2,981$. & 6 \\
$57,500$. & 878. & 0. \\
\hline $157,000$. & 3,859 ps. 6.
\end{tabular}


Este sumario se compone de ciento cinquenta y siete mil adobes, comprados, y mandados haser, y de tres mil ochocientos cinquenta y nuebe pesos y seis reales que importaron, como parece de su demonstracion.

\section{[Rúbrica de Miguel de Echeverría]}

Data de los pessos que se pagan al maestro cantero y oficiales de labrar por su trabajo, conducion y costo de las piedras de silleria que se conduxeron, para las obras del real palacio de esta ciudad.

Se dan en data un mil quatrocientos sesenta y tres pessos dos reales y medio que se pagaron al maestro de canteria Ventura Valencia, por su travajo, conducion de treinta y quatro cargas de piedra de silleria, y por los jornales de los demas oficiales labradores que con el trabajaron en las obras del real palacio, como consta de veinte y siete recivos suyos y boletas de los maestros alarifes, don Cristoval de Vargas, y Pedro de los Reyes, que van recados de esta partida, con advertencia de que estan inclussos en la dicha cantidad, trescientos treze pessos quatro reales que recivio el dicho alarife don Cristoval de Vargas, para pagar los jornales de los oficiales canteros, que havian trabajado, hasta quince de junio de mil setecientos quarenta y nuebe, cuyo recivo esta inclusso en el numero de los expresados veinte y siete.

Miguel de Echeverria [Rubricado]

[Crismón]

Data de las cantidades de pessos que se pagan por razon de las fanegas de cal, que se compran para las obras del real palacio desta ciudad.

Se dan en data, quatro mil seiscientos veinte y tres pessos que se pagaron a diferentes dueños de las caleras de este material por otras tantas fanegas que hecharon para las obras del real palacio de esta ciudad, a razon de ocho reales cada fanega, yncluyendo en ella su conducion, como consta de diez y siete voletas del maestro alarife don Cristoval de Vargas, y otros tantos recivos de los dichos dueños que van por recados de esta partida inclusso en ellos uno de cinquenta y dos pessos, y quatro reales por el valor de mil setecientos, y cinquenta ladrillos de labrar, a 4,623.0. razon de treinta pessos millar.

$$
\text { Miguel de Echeverria [Rubricado] }
$$


Ydem Assimismo se dan en data, trescientos, y quatro pessos, por el importe de treinta y ocho cayzes de cal, que hecharon para las expresadas obras del real palacio, de la calera // de los padres bethlemitas, a razon de ocho pessos cada caiz que hazen quatroçientas y cinquenta y seis fanegas como consta de dos voletas del citado alarife don Cristoval de Vargas, y dos recivos del padre procurador fray Juan de la Visitassion que van por recados de esta partida la que se pone separada, por la diferencia de un precio a otro respecto de ser de mas equidad la que se expressa que la que va citada en la partida antesedente, pero los dos dichos recivos van a continuacion de los primeros diez y siete.

\section{Miguel de Echeverria [Rubricado]}

Sumario de las fanegas de cal y su importe

$$
\begin{aligned}
4,623 . & 4,623 . \\
456 . & 304 . \\
5,079 . & 4,927 \mathrm{ps} .
\end{aligned}
$$

Este sumario se compone de cinco mil setenta y nuebe fanegas, y de quatro mil nobecientos, veinte y siete pessos que importaron como se reconoce por su demonstrassion.

[Rúbrica de Miguel de Echeverría]

\section{[Crismón]}

Data de las cantidades de pessos que se gastaron en los ladrillos de solar, que se compraron para las obras del Rey del palacio de esta ciudad.

Ydem de Se dan en data, un mil quinientos setenta y nuebe pessos, y labrar seis reales que se han pagado, por el valor, de quarenta y quatro mil y setecientos ladrillos de solar que han hechado de diferentes caleras, para las obras del real palacio, a razon de treinta y ocho pessos algunos millares, a treinta y cinco pessos los mas de ellos, y a veinte y ocho, y treinta y tres otros, como todo consta de diez y ocho voletas del maestro alarife don Cristoval de Vargas, y recivos de los ynteresados, a quienes se les han hecho las pagas, que van por recados de esta partida.

Miguel de Echeverria [Rubricado]

Assimismo se dan en data, un mil ochocientos quarenta y seis pessos, que se pagaron, por el valor de sessenta y seis mil doscientos y dos ladrillos de labrar, que se compraron de 
diferentes caleras, para las obras del dicho real palacio // a varios precios, procurando el mayor ahorro de la Real Hazienda, como consta de treinta voletas del maestro alarife don Cristoval de Vargas, y de otros tantos recivos de los sugetos que fueron interesados en su importe, los quales van por recados de esta partida, en la que se dize ser treinta voletas y recivos (como de facto lo son) pero se advierte que no constan mas que de veinte y seis papeles.

Miguel de Echeverria [Rubricado]

Sumario de los millares de ladrillos y su importe

\begin{tabular}{cl}
$44,700$. & 1,579 ps. 6 \\
$66,202$. & $1,846$. \\
\hline 110,902 millares & 3,425 ps. 6.
\end{tabular}

Este sumario se compone de ciento diez mil nobecientos y dos millares de ladrillos, de las calidades que se expresan, y de tres mil quatrocientos veinte y cinco pessos y seis reales que importaron como se reconose esa demonstracion.

[Rúbrica de Miguel de Echeverría]

[Crismón]

Data de los pessos que se pagan por las requas de polvo que se hecha para las obras del real palacio de esta ciudad.

Se dan en data ciento sesenta y nuebe pessos, que se pagaron a Clemente de Acosta, por el valor de trescientos y treinta y ocho viajes de a doce borricos cada uno de polvo, que hecho en sus requas, para las obras de dicho real palacio, a razon de quatro reales cada uno, en que se incluyen, algunos de zeniza para los techos, y otros de tierra de sembrar para el gardin, como todo consta de diez y nuebe voletas del maestro alarife, y otros tantos recivos del sussodicho, que van por recados de esta partida.

Miguel de Echeverria [Rubricado]

\section{[Crismón]}

Data de los pessos que se pagaron por el importe de los viajes de arena que se hecho para las obras del real palacio de esta ciudad.

Se dan en data, quinientos sesenta y tres pesos y siete reales que se pagaron, por el valor de novecientos, y dos viajes 


\section{CHARLES WALKER Y RICARDO RAMÍREZ CASTAÑEDA}

de arena de a doce borricos, que hecho Clemente de Acosta, a cinco reales cada uno, para las obras del real palacio, como consta de treinta y seis voletas del maestro alarife don Cristoval de Vargas, y otros tantos recivos del dicho Clemente, que van por recados de esta partida.

Miguel de Echeverria [Rubricado]

Data de las cantidades de pessos, que se pagan por razon de conducir la piedra que se necessita, para las obras del real palacio de esta ciudad, assi la que se trajere del puerto del Callao, como la de zerro, de rio, y de empedrar.

Se dan en data, quinientos veinte y siete pessos que se pagaron, por treinta y nuebe carretadas de piedras que se conduxeron del puerto del Callao, para las obras del dicho real palacio, a razon de ocho pessos cada carretada, que hazen trescientos y doce pessos, y doscientas y quince cargas de mula, a razon de ocho reales que hazen los mismos doscientos y quince pessos, y ambas cantidades componen la de los expressados quinientos veinte y siete pessos, como consta de ocho voletas del maestro alarife don Cristoval de Vargas, y otros tantos recivos comprehendidos en siete papeles que van por recados de esta partida.

Miguel de Echeverria [Rubricado]

Ydem Assimismo se dan en data, trescientos setenta y seis pessos, que se pagaron a Clemente de Acosta, por ciento ochenta y ocho viajes // de piedra de cerro que hecho para las obras del citado real palacio, a razon de dos pessos cada viaje, como consta de diez recivos suyos, que van por recados de esta partida, con las voletas del maestro alarife don Cristoval de Vargas.

Miguel de Echeverria [Rubricado]

Ydem Assimismo se dan en data, doscientos treze pessos quatro reales que se pagaron, al sobre dicho Clemente de Acosta, por quatrocientos veinte y siete viaxes de piedra de rio, que hecho para las referidas obras del real palacio a razon de quatro reales cada uno, como consta de ocho voletas del maestro alarife don Cristoval de Vargas, y otros tantos recivos del dicho Clemente, que van por recados de esta partida.

527.0.

\section{Miguel de Echeverria [Rubricado]}

Ydem Assimismo se dan en data setenta y cinco pesos quatro reales que se pagaron al expressado Clemente de Acosta, por ciento cinquenta y un viaxes de piedra de empedrar, que hecho para los patios, // cavallerisas, sala de armas, y 
demas oficinas del dicho real palacio, a razon de quatro reales cada uno, como consta de seis voletas del maestro alarife, y otros tantos recivos del sussodicho, que van por recados de esta partida.

75.4 .

\section{Miguel de Echeverria [Rubricado]}

Ydem De la propria suerte se dan en data diez y ocho pesos que se pagaron al mismo Clemente de Acosta, por seis requas de lozas que hecho, para algunas obras precissas de dicho real palacio, a razon de tres pesos cada requa, como consta de voleta, y recivo que va por recado de esta partida.

Miguel de Echeverria [Rubricado]

Sumario de las cantidades que importan las porciones de piedra, segun sus precios y calidades, como van expressadas, y del importe de su valor

\begin{tabular}{lrlr} 
Carretadas. & 39. & a 8 ps. & 312 ps. \\
Mulas. & 215. & a 1 ps. & 215 ps. \\
Viaxes. & 188. & a 2 ps. & 376 ps. \\
Viaxes. & 427. & a 4 rs. & 213 ps.4. \\
Viaxes. & 151. & a 4 rs. & 75 ps.4. \\
Viaxes. & 6. & a 3 ps. & 18 ps.0. \\
\hline & & & 1,210 ps.0.
\end{tabular}

Ymporta el gasto de la conducion de las piedras que se expresan en las partidas de arriba un mil doscientos y diez pessos como parece.

[Rúbrica de Miguel de Echeverría]

\section{[Crismón]}

Data de los pessos que se pagan por el costo de los costales de paxa que se hechan para las obras del real palacio de esta ciudad.

Se dan en data, doscientos noventa y un pesos y dos reales que se pagaron, a don Francisco Xinester y Arguelles, por un mil ciento sesenta y cinco costales de paxa que hecho para las obras del dicho real palacio, a razon de dos reales cada uno, que hacen la misma cantidad, como consta, de ocho voletas del maestro alarife don Cristoval de Vargas, y otros tantos recivos del expressado don Francisco que van por recado de esta partida.

Miguel de Echeverria [Rubricado] 


\section{CHARLES WALKER Y RICARDO RAMÍREZ CASTAÑEDA}

[Crismón]

Data de los pessos que se pagan por el yesso que se compra para las obras del real palacio de esta ciudad.

Se dan en data, noventa y un pessos cinco reales y medio, que se pagaron por el valor de doscientas y setenta y quatro arrobas de yesso, compradas a razon de a tres reales las noventa y siete de ellas, y las ciento setenta y siete restantes, a razon de a dos reales y medio, en virtud de dos libranzas del maestro alarife don Cristoval de Vargas, que van por recados de esta partida.

Miguel de Echeverria [Rubricado]

[Crismón]

Data de los pesos que se pagan por razon de tazar los desmontes que hay que hechar fuera del real palacio, y su contorno.

Se dan en data, diez y ocho pessos, que se pagaron a los maestros Juan Gregorio, y Lugardo Bravo, por la tazassion, que hicieron de las porciones de desmontes que havia que sacar del real palacio, y sus contornos, como consta de dos recivos suyos que van por recado de esta partida.

Miguel de Echeverria [Rubricado]

\section{[Crismón]}

Data de los pessos que se pagan por razon de sacar los desmontes del real palacio de esta ciudad.

Se dan en data, novecientos y cinquenta pessos que se pagaron a Clemente de Acosta, por la limpia y saca de los desmontes, desde el palacio y su contorno, los quatrocientos en virtud de aprovacion de los señores ministros de la junta de fabrica, de veinte y dos de febrero de setecientos quarenta y nuebe, y los quinientos, y cinquenta restantes, en virtud de otra aprovacion posterior, como de ellas consta, y de una libranza, y de tres recivos del dicho Clemente de Acosta, que todo va por recado de esta partida.

Miguel de Echeverria [Rubricado]

Ydem Assimismo da en data, setenta y quatro pesos dos reales y medio que se pagaron al enunciado Clemente de Acosta, por el desmonte de los caxones de alquiler que estan ingeridos en el dicho real palacio, como consta de quatro vole- 
tas del maestro alarife, y otros quatro recivos del sussodicho, que van por recado de esta partida.

$74.2 \frac{1}{2}$

Miguel de Echeverria [Rubricado]

Sumario del gasto de los desmontes

$$
\begin{gathered}
950 \text { ps. } \\
74 \text { ps. } 2^{1 / 2} . \\
\hline 1,024 \text { ps. } 2^{1 / 2} .
\end{gathered}
$$

Este sumario ymporta un mil veinte y quatro pesos dos reales y medio que se pagaron por la limpia y saca de los desmontes en la conformidad que se expressa, como se reconoce.

[Rúbrica de Miguel de Echeverría]

\section{[Crismón]}

Data de los pessos que se pagan, por la conducion de algunos cañones de artilleria que se mandan traer del precidio del Callao para el real palacio de esta ciudad.

Se dan en data, treinta y dos pessos, que se pagaron, a don Joseph Palomino, y Miguel Carrillo, por la conducion, de seis piessas de artilleria, en quatro carretas, a razon de ocho pessos cada una que traxeron desde el puerto del Callao, a el real palacio de esta ciudad, como consta, de dos voletas y dos recivos que van por recado de esta partida.

Miguel de Echeverria [Rubricado]

\section{[Crismón]}

Data de ochenta y cinco pessos, y quatro reales que se pagaron por el valor, de un perol de cobre en que cosinassen los negros de Su Majestad que se compro a razon de ocho reales libra, el qual pesso ochenta y cinco libras y media, como consta de la libranza de don Juan Calixto, y recivo al pie de ella, de la persona que lo recivio, que va por recado de esta partida.

Miguel de Echeverria [Rubricado]

$$
\text { [Crismón] }
$$

Data de los pesos que se pagan por razon de las erramientas, que se compran, para las obras del real palacio de esta ciudad.

Se dan en data, doscientos çinquenta y siete pessos, y un real, que se pagaron en esta manera, los setenta y siete pessos, 


\section{CHARLES WALKER Y RICARDO RAMÍREZ CASTAÑEDA}

por el valor de seis arrobas y quatro libras de fierro bergajon, para hacer barretas, a razon de cinquenta pesos quintal, seis pessos y un real por siete libras de azero de Milan a siete libras, y treinta y nuebe pessos por el precio de quatro barretas hechas en España, y calzadas de azero, que pessaron quarenta y ocho libras, a razon de seis reales y medio, doce lampas de fierro a cinco pessos y quatro reales y seis palas tambien de fierro, a quatro pesos y quatro reales, y otras seis lampas a razon de siete pessos, que todas las dichas especies componen la primera expresada cantidad, como consta de tres recivos que van por recados de esta partida.

Miguel de Echeverria [Rubricado]

Assimismo se ponen en data, nuebe pesos y cinco reales que se pagaron por el valor // de veinte y dos baras de beta embreada que se compró para subir el barro a los techos, para hacer los adobes, como consta de un recivo que va por recado de esta partida.

Miguel de Echeverria [Rubricado]

Sumario de estas dos partidas

$$
\begin{array}{rr}
257 . & 1 . \\
9 . & 5 . \\
266 & \text { ps. } 6 .
\end{array}
$$

Ymporta este sumario, doscientos sesenta y seis pessos y seis reales, que se pagaron por las erramientas compradas, como parece de su demostracion.

[Rúbrica de Miguel de Echeverría]

\section{[Crismón]}

Data de los pessos que se gastan en comprar la clabazon que se necesita para las obras del real palacio de esta ciudad.

Se dan en data, trescientos ochenta y tres pessos, y tres reales que se pagaron por el valor de los cajones de clavos de entablar, que pesaron trescientas ochenta y cinco libras y media netas a razon de ochenta pessos quintal, y otro caxon dicho de barrote, con ciento y cinquenta libras netas a razon de cinquenta pesos el quintal, como todo consta de tres voletas y tres recivos que van por recados de esta partida.

Miguel de Echeverria [Rubricado] 
Data de las cantidades de pessos que se pagan a los erreros, por varias obras de su facultad que executan para las que necesita la fabrica del real palacio de esta ciudad.

Se dan en data dos mil doscientos setenta y nuebe pesos y cinco reales que se pagaron a los maestros erreros, por diferentes obras de erreria que han hecho, para las pertenecientes al dicho real palacio, en varios dias y tiempos, como consta de treinta y siete voletas del maestro carpintero, y otros tantos recivos de dichos erreros y suyos, que van por recados de esta partida.

Miguel de Echeverria [Rubricado]

\section{[Crismón]}

Data de las cantidades de pessos que se pagan a los peones jornaleros, que trabajan en las obras del real palacio de esta ciudad.

Se dan en data, quince mil nobenta y siete pesos y dos reales que se pagaron a diferentes peones jornaleros, que trabajaron, en las obras del real palacio de esta ciudad, desde el dia juebes veinte y seis de septiembre, de mil setecientos y quarenta y ocho, hasta el sabado, dies y ocho de septiembre de mil setecientos y cinquenta y uno, inclusive uno y otro, a razon de a seis reales menos los barreros, a quienes se les pagaron a ocho reales como todo consta de un quaderno que se compone de ciento y cinquenta y seis foxas en que van por secuela los años que se citan, y otras tantas listas y memorias semanales firmadas de mi el dicho sobrestante, y de los dos maestros de albañileria y carpinteria don Cristoval de Vargas, y Pedro de los Reyes, que se ponen por recados de esta partida.

Miguel de Echeverria [Rubricado]

15,097. ps.2.

\section{[Crismón]}

Data de las cantidades de pessos que se pagan por razon de sus jornales al maestro carpintero y demas oficiales que trabajan en las obras del real palacio de esta ciudad.

Se dan en data, diez y ocho mil nobeçientos treinta y dos pessos, y seis reales que se pagaron al maestro carpintero Pedro de los Reyes, y demas oficiales mayores y menores de este arte, desde el dia diez y ocho de septiembre de mil setecientos quarenta y ocho, hasta el dos de octubre de mill setecientos cinquenta y uno, inclusive uno, y otro, 


\section{CHARLES WALKER Y RICARDO RAMÍREZ CASTAÑEDA}

como consta de ciento y çinquenta y ocho listas, memorias, semanales, y recivos del expressado maestro Pedro de los Reyes que van por recados de esta partida.

Miguel de Echeverria [Rubricado]

[Crismón]

Data de las cantidades de pessos, que se pagan por la madera que se compra, para las obras del real palacio de esta ciudad.

Se dan en data, siete mil setecientos treinta y tres pesos tres reales y medio, que se pagaron por el valor de tres mil ochocientas çinquenta y cinco baras y dos tercias de alfaxia de hacha compradas para las obras de dicho real palacio, a diferentes sugetos y variedad de pessos segun su calidad, como todo consta de nuebe recivos y cartas de pago de los dueños que percivieron la plata de su importe, las quales van por recados desta partida.

$7,733.3^{1 / 2}$

Miguel de Echeverria [Rubricado]

[Crismón]

Data de los pessos que se pagan a los conductores de la madera de la playa del Callao para las obras del real palacio desta ciudad.

Se dan en data ochocientos çinquenta y quatro pesos que se pagaron a diferentes arrieros por las alfaxias que conduxeron desde las playas del Callao para las obras del real palacio de esta ciudad, assi enteras de a ocho varas, como trozos varios regulados a la proporcion de las enteras a razon de ocho reales cada una, como todo consta de sesenta y seis voletas del maestro carpintero Pedro de los Reyes, y otros tantos recivos de los arrieros conductores que van por recados desta partida.

854.0.

Ydem en Miguel de Echeverria [Rubricado]

carretas

Assimismo se dan en data novecientos setenta y seis pesos que se pagaron por ciento veinte y dos carretadas de buelles, que conduxeron las alfaxias de monte Morales, mauras negras, y otras de mucho pesso a razon de ocho pessos cada carretada, con aprobacion de los señores ministros de la junta de fabrica, para las obras de dicho real palacio, como todo consta de diez voletas del maestro carpintero, y diez recivos de los dueños // de las dichas carretas, que todos juntamente con el citado auto de aprobacion de cada carretada van por recados de esta partida.

Miguel de Echeverria [Rubricado]

976.0. 


\section{LA RECONSTRUCCIÓN DEL REAL PALACIO DE LIMA, 1746}

Sumario de las cantidades de la conducion de madera

$$
\begin{gathered}
854 . \\
976 . \\
\hline 1,830 \text { ps. } 0 .
\end{gathered}
$$

Ymporta este sumario del costo de las conduciones de madera un mil ochocientos y treinta pessos, como parece.

[Rúbrica de Miguel de Echeverría]

\section{[Crismón]}

Data de los pessos que se pagan a los azerradores de la madera que se dispone para las obras del real palacio de esta ciudad.

Se dan en data, dos mil trescientos veinte y siete pessos, y tres reales que se pagaron a varios yndividuos acerradores, por ochocientas setenta y dos tarcas y media, que açerraron en diferentes dias y tiempos de las maderas necessarias, para las obras de dicho real palacio, a razon de tres pessos y quatro reales algunas de las primeras tarcas despues otras a veinte y dos reales y las ultimas a veinte reales, como todo consta de ciento y veinte y cinco voletas firmadas del maestro carpintero Pedro de los Reyes, numeradas, desde numero dos, hasta el numero ciento y veinte, y seis, entre las quales por equibocacion, se numero un recivo de nuebe pesos y seis reales de dos chapas que se compraron, que es el numero ciento, y veinte y cinco, y todas van por recados de esta partida, inclusso el dicho recivo.

Miguel de Echeverria [Rubricado]

\section{[Crismón]}

Data de los pessos que se pagan a los torneros, por razon de tornear los balaustres que necessitan las obras del real palacio de esta ciudad.

Se dan en data, ciento sinquenta y tres pessos que se pagaron, al tornero Joachin del Valle, por quinientos quarenta y nuebe balaustres, que torneo, para los corredores que caen al jardin de dicho real palacio, a razon de dos reales cada uno, y nuebe pilarotes, a razon de catorce reales como consta de dos voletas del maestro Pedro de los Reyes, y dos recivos del dicho tornero, que van por recados de esta partida.

$$
\text { Miguel de Echeverria [Rubricado] }
$$


Ydem mas Assimismo se dan en data, noventa y un pesos y seis reales pequeños. que se pagaron al sobredicho tornero, Joachin del Valle, por el trabajo de haver torneado, sesenta y seis docenas y diez balaustres menores, para las puertas y bentanas del dicho real palacio, como consta de su recivo y voleta del maestro carpintero que va a continuacion de los dos antesedentes, y sirve de ynstruccion de esta partida.

91.6.

Miguel de Echeverria [Rubricado]

Sumario de las cantidades que se pagaron al tornero, por el trabajo de tornear los balaustres

153.

91. 6.

244 ps. 6

Ymporta este sumario, doscientos quarenta y quatro pesos seis reales como parece de su demonstracion.

[Rúbrica de Miguel de Echeverría]

[Crismón]

Data de los pessos que se gastan en pagar las porciones de caña braba, que se compran para las obras del real palacio de esta ciudad.

Se dan en data, un mil ochenta pessos y cinco reales que se pagaron por el valor de seiscientas, y sessenta y cinco cargas de caña braba, que se compraron, para las obras del real palacio en diferentes dias, y tiempos a varios sugetos, a razon de treze reales cada carga, como consta de diez y ocho voletas del maestro carpintero Pedro de los Reyes, que se incluyen en diez y siete papeles, los quales van por recados de esta partida.

Miguel de Echeverria [Rubricado]

$1,080.5$.

\section{[Crismón]}

Data de los pessos que se pagan, por el valor de las tablas que se compran para las obras del real palacio de esta ciudad, y por el flete de la conducion de ellas desde el puerto del Callao.

Se dan en data, quinientos ochenta y un pesos y dos reales, que se pagaron por el valor de seiscientas y veinte tablas de Chilué, a razon de siete reales y medio, a don Manuel 
Gallo Diaz, como consta de su carta de pago, que va por $\quad$ 581.2. recado de esta partida.

Miguel de Echeverria [Rubricado]

Ydem por la Assimismo se dan en data, ciento quarenta y dos pesos y quaconducion tro reales que se pagaron a Bernabe de los Rios, arriero por de tablas.

\begin{abstract}
el flete y conducion de tres mil trescientas y veinte tablas de Chilue, como consta de cinco voletas del maestro carpintero Pedro de los Reyes, y de otros tantos recivos del sussodicho, que aunque en el uno de ellos se da por entregado de treinta y un pessos, se advierte que los seis pertenecen a la conduccion de alfaxias en cuya data estan incluidos, y solamente se ponen en esta veinte y cinco pesos por razon del flete de las dichas tablas, y los expresados recivos, y voletas van por recados de esta partida.
\end{abstract}

Miguel de Echeverria [Rubricado]
142.4 .

Sumario del ymporte de tablas compradas, y conducion de ellas, desde el puerto del Callao a esta ciudad

\begin{tabular}{ll} 
Costo & 581.2. \\
Conducion & 142.4. \\
\cline { 2 - 2 } & 723.6
\end{tabular}

Ymporta este sumario de las tablas compradas, y su conducion setecientos veinte y tres pessos y seis reales como se reconoce en su demonstracion.

[Rúbrica de Miguel de Echeverría]

\section{[Crismón]}

Data de los pessos, que se gastan en la ropa de la tierra que se compra, para los bestuarios de los negros de Su Majestad y en sus hechuras al maestro sastre.

Se dan en data, doscientos setenta y tres pesos quatro reales y medio, que se pagaron por las piesas de ropa de la tierra, que se compraron, en varios dias y tiempos para los vestuarios de los negros esclavos de Su Majestad en esta manera, ciento catorze reales de bayeta azul, a dos reales y quartillo; ciento diez y seis baras de dicha bayeta, a tres reales y medio; ciento cinquenta y seis baras de pañete azul, a tres reales y tres quartillos; ciento y quince baras de dicho pañete, a quatro reales; y ciento treinta y siete baras y media de cordellates, a tres reales y medio, como consta, de quatro recivos de los sugetos a quienes se compraron las dichas expecies, que van por recados de esta partida. $273.41 \frac{1}{2}$ Miguel de Echeverria [Rubricado] 


\section{CHARLES WALKER Y RICARDO RAMÍREZ CASTAÑEDA}

Ydem. $\quad$ Assimismo se dan en data, trescientos diez y siete pessos y seis reales que se pagaron al maestro sastre que hizo los bestidos de los negros de Su Majestad, assi por el costo de una pieza de cordellate, con cinquenta, y dos baras a quatro reales; una pieza de bayeta, con sessenta y cinco baras, y un retazo mas de seis baras, a tres reales, como por razon del costo de todas las echuras // lo qual consta de cinco memorias y recivos del sussodicho, que van por recados de esta partida.

Miguel de Echeverria [Rubricado]

Sumario del costo de la ropa de la tierra, y echuras de los bestuarios de los negros de Su Majestad.

\begin{tabular}{ll}
273. & $41 / 2$. \\
317. & 6. \\
\hline 591 & ps. $21 / 2$
\end{tabular}

Ymporta este sumario, quinientos nobenta y un pessos dos reales y medio, como parece de su demonstracion.

[Rúbrica de Miguel de Echeverría]

[Crismón]

Data de los pessos que se pagan para comprar frezadas, y ponchos para los negros esclavos de Su Majestad.

Se dan en data, ciento sesenta y tres pesos y tres reales que se pagaron por el costo de cinquenta y tres frezadas, las veinte y nuebe a dos pesos, con mas tres reales de su conducion, y las veinte y quatro a quince reales, y veinte y quatro ponchos, a veinte reales cada uno, que todo importa, la expressada cantidad, como consta, de tres recivos que van por recados de esta partida.

Miguel de Echeverria [Rubricado]

\section{[Crismón]}

Data de los pesos que se gastan en baptissar los negros bozales esclavos de $\mathrm{Su}$ Majestad.

Se dan en data, quarenta y ocho pessos, que se pagaron por baptissar veinte y quatro negros bozales esclavos de $\mathrm{Su}$ Majestad a razon de dos pessos cada uno como consta de un recivo del lizenciado don Salvador Ubaldo de Castro, 
theniente de cura de la yglesia mayor de esta ciudad, que va por recaudo de esta partida.

Miguel de Echeverria [Rubricado]

[Crismón]

Data de los pesos que se gastan, en la enzeñanza de la doctrina christiana a los negros bozales esclavos de Su Majestad.

Se dan en data, doscientos y diez pessos, que se pagaron al padre fray Juan de Valenzuela del orden de Predicadores, por enseñar la doctrina christiana, y catetissar a los negros bozales esclavos de Su Majestad a razon de diez pessos cada mes, en los veinte y uno, que se empleó en esta ocupacion, hasta el dia primero de julio, de mil cetecientos çinquenta y un años, cuya cantidad le señalaron los señores ministros de la junta de fabrica por decreto de dicho dia primero de julio de setecientos sinquenta y uno, que va por recado de esta partida junto con el recivo del çitado padre fray Juan de Valenzuela.

Miguel de Echeverria [Rubricado]

[Crismón]

Data de los pessos que se pagan por los entierros de los negros bozales esclavos de Su Majestad que se van muriendo.

Se dan en data, sesenta y quatro pesos, y quatro reales que se pagaron por los entierros de seis negros bozales esclavos de $\mathrm{Su}$ Majestad que murieron y se enterraron en el Hospital de San Bartholome de esta ciudad, como consta de seis recivos del doctor don Diego de Frias su capellan, que van por recados de esta partida.

64.4 .

Miguel de Echeverria [Rubricado]

[Crismón]

Data de los pessos que se gastan, en la curacion de los negros bozales enfermos esclavos de Su Majestad.

Se dan en data, veinte y un pessos seis reales que se pagaron por veinte y nuebe dias que estubo enfermo curandose un negro bozal esclavo de Su Majestad nombrado Christoval, en el Hospital del Espiritu Santo a razon de seis reales en cada uno de ellos, como consta de un recivo 


\section{CHARLES WALKER Y RICARDO RAMÍREZ CASTAÑEDA}

de don Francisco Garvi Carbonel, mayordomo de dicho Hospital, que va por recado de esta partida.

21.6.

Miguel de Echeverria [Rubricado]

[Crismón]

Data de los pessos que se pagan a los empedradores que empedraron los patios, callejones, cavallerisas, cocheras, y lo demas que se ofreze en el real palacio de esta ciudad.

Se dan en data, doscientos doce pesos y cinco reales que se pagaron a Vizente negro empedrador y sus peones, por un mil setecientas varas, y media, que empedraron en los patios, callexones, cavallerisas, cocheras, cuerpos de guardias, y otras partes de dicho real palacio, a razon de un real cada vara, como consta, de quince voletas libranzas del maestro alarife don Cristoval de Vargas, que van por recados de esta partida.

212.5 .

Miguel de Echeverria [Rubricado]

[Crismón]

Data de los pessos que se pagan al ojalatero, por las obras de su facultad que tiene que hacer en el real palacio de esta ciudad.

Se dan en data cinquenta y dos pessos, que se pagaron a Manuel de Roxas, oficial de ojalatero por algunas obras que executó de su arte, en dicho real palacio, como consta de tres recivos suyos que van por recados de esta partida.

Miguel de Echeverria [Rubricado]

[Crismón]

Data de los pesos que se pagan por razon de los cueros que se compran para las obras del real palacio de esta ciudad.

Se dan en data, noventa y seis pesos y seis reales que se pagaron a don Augustin Carrion, por el importe de quarenta y ocho cueros de novillos de Chile que se le compraron, para las obras de dicho real palacio al precio de dos pesos cada uno, como consta de su recivo que va por recado de 96.6. esta partida.

Miguel de Echeverria [Rubricado] 
Data de los pesos que se pagan por razon de las pinturas que se hicieron en dicho real palacio de esta ciudad.

Se dan en data, un mil ochenta y ocho pesos y quatro reales que se pagaron por las pinturas, y azulexos, sintas, balcon, puertas, y corredores del real palacio de esta ciudad, a los maestros Cayetano Valverde, y Pedro Nolasco, como consta de seis recivos suyos, que van por recados de esta partida.

Miguel de Echeverria [Rubricado]

[Crismón]

Data de los pessos que contiene una memoria jurada gastados en varias menudencias, y otras cosas particulares.

En veinte y siete de octubre de mil setecientos çinquenta y un años, da en data, siete mil quarenta y un pessos, un real y medio, que se gastaron en varias menudencias, y diferentes cossas particulares, que en virtud de decreto que para ello tube del Superior Govierno, de siete de noviembre, de mil setecientos quarenta y ocho, como todo consta de una memoria jurada y firmada que se presento, y va por recado de esta partida.

$7,041 \cdot 1 \frac{1 / 2}{2}$

Miguel de Echeverria [Rubricado]

[Crismón]

Sumario general de todas las partidas de data, que contiene este libro

\begin{tabular}{|c|c|c|c|c|}
\hline 7,536 ps. 2 . & 527 ps.0. & 32 ps. 0. & 976 ps.0. & 48 ps. 0. \\
\hline 2,981 ps. 6. & 376 ps.0. & 85 ps. 4 . & 2,327 ps. 3 . & 210 ps.0. \\
\hline 878 ps.0. & 213 ps. 4 . & 257 ps.1. & 153 ps.0. & 64 ps.4. \\
\hline 1,463 ps. $2^{1 / 2}$ & 75 ps. 4 . & 9 ps.5. & 91 ps.6. & 21 ps.6. \\
\hline 4,623 ps. & 18 ps. 0. & 383 ps.3. & 1,080 ps.5. & 212 ps.5. \\
\hline 304 ps. & 291 ps. 2 . & 2,279 ps. 5 . & 581 ps.2. & 52 ps.0. \\
\hline 1,579 ps.6. & 91 ps. $51 / 2$ & 15,097 ps.2. & 142 ps.4. & 96 ps.6. \\
\hline 1,846 ps. 0 . & 18 ps.0. & 18,932 ps. 6. & 273 ps. $41 / 2$ & 1,088 ps. 4. \\
\hline 169 ps.0. & 950 ps.0. & 7,733 ps. $31 / 2$ & 317 ps.6. & 7,041 ps. $11 \frac{1}{2}$ \\
\hline 563 ps.7. & 74 ps. $2^{1 / 2}$. & 854 ps.0. & 163 ps.3. & \\
\hline
\end{tabular}

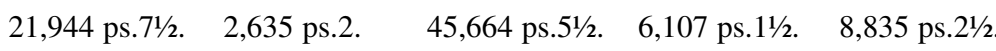




\section{CHARLES WALKER Y RICARDO RAMÍREZ CASTAÑEDA}

\begin{tabular}{cll}
\multicolumn{3}{c}{ Sumas mayores } \\
21,944 ps. $71 \frac{1}{2}$. & Cargo & $79,389 \mathrm{ps} .4$. \\
$2,635 \mathrm{ps} .2$. & Data & $85,187 \mathrm{ps} .3$. \\
, $664 \mathrm{ps} .5^{1 / 2}$. & Alcanzo & $5,797 \mathrm{ps} .7 \mathrm{rs}$. \\
$6,107 \mathrm{ps} .1^{1 / 2 .}$. & & \\
$8,835 \mathrm{ps} .2^{1 / 2 .}$. & & \\
\hline $85,187 \mathrm{ps} .3 \mathrm{rs}$. &
\end{tabular}

Por manera que ymporta este sumario general de todas las partidas de data de este libro que corren desde folio 7 hasta folio 44 ochenta y cinco mil ciento ochenta y siete pesos y tres reales de a ocho; y siendo el cargo setenta y nuebe mil trescientos ochenta y nuebe pesos y quatro reales que se contienen desde folio 1 hasta folio 6 resultan a mi favor, cinco mil setecientos nobenta y siete pessos y siete reales en que alcanzo, por los suplementos que tengo hechos, para que, se continuasen las obras de dicho real palacio sin sezar, por causa de no librarseme promptamente las cantidades necessarias, como se reconoce de la demonstracion de arriba, y juro a Dios Nuestro Señor y a una señal de cruz [cruz] que todo, lo expressado y contenido en esta quenta, es cierto, y verdadero sin dolo, fraude, ni encubierta contra la Real Hacienda, y para que conste lo firme. Lima y noviembre doce, de mil setecientos çinquenta y uno.

[Rúbrica de Miguel de Echeverría]

Advertencia

Advierto que de las expecies de clabazon fierro, y azero que manexé, para las obras del dicho real palacio de esta ciudad assi las que se me entregaron de quenta de $\mathrm{Su}$ Majestad como las que yo compre por mi mano sobraron las porciones que constan de un recivo de don Juan Carrillo, sobrestante nuebo nombrado para las dichas obras, y otro del maestro errero Cayetano del Aguila, como de ellos consta, y los precento con esta advertencia, como tambien un testimonio authorisado de la carta de pago que di, a favor de los oficiales reales desta Caja, al tiempo que me entregaron los expressados efectos, que pertenecian a Su Majestad que assimismo va por recado que ynstruya esta razon. Lima y noviembre doce de mil setecientos, çinquenta y uno.

Miguel de Echeverria [Rubricado]

\section{Otra advertencia}

Adviertese tambien, que respecto de la retardacion de los libramientos de plata, y no poder yo suplir mas cantidades de las que van expressadas en esta quenta se estan devien- 
do de materiales gastados en las obras del dicho real palacio, un mil quinientos nobenta y ocho pesos // y quatro reales en esta forma. Novecientos, nobenta y çinco pessos, a la calera de la religión de San Augustín, procedidos de noventa y seis caysses de cal, y un mil ladrillos de solar; setenta y siete pessos y quatro reales a la calera de la religion de los padres bethlemitas, proçedidos de cinco cayzes de cal, y mil, y quinientos ladrillos de labrar; quatrocientos, y sesenta pessos, a don Joseph del Villar, y Andrade, por otras tantas tablas de Chilué, y sessenta y seis pesos al maestro pintor, de resto de las pinturas que hizo en dicho Palacio; de cuyas partidas tengo dados vales a los expressados ynteresados, para que ocurran a $\mathrm{Su}$ Excelencia y les mande siendo servido satisfazer estos creditos, por ser justamente recomendables. Lima y noviembre doce de mil setecientos çinquenta y uno.

Miguel de Echeverria [Rubricado] 


\section{Mano de obra}

Maestro carpintero y oficiales

Peones jornaleros

Maestro alarife y oficiales de albañilería

Aserradores de madera

Maestros herreros

Maestro y oficiales de cantería (incluye fletes)

Maestros pintores

Tornero

Empedrador y peones

Oficial hojalatero

\section{Materiales}

Madera

Cal (incluye fletes)

Adobes

Ladrillos de labrar

Ladrillos de solar

Caña brava

Tablas de "Chilue"

Clavazón

Paja

Herramientas

Cueros de novillos

Yeso

\section{Transporte}

Madera

Desmonte

Arena

Piedra de Callao

Piedra de cerro

Piedra de río

Recuas de polvo

Tablas de "Chilue"

Piedra de empedrar

Cañones de artillería

Desmonte (tasación)

Lozas

\section{Esclavitud}

\section{Sastre}

Ropa de la tierra (material)

Enseñanza de la doctrina cristiana

Frazadas y ponchos

Perol de cobre (cocina)

Entierros

Bautismos

Curación de enfermos

\section{Menudencias}

$$
\begin{array}{r}
18,932,, 6.0 \\
15,097,6.0 \\
7,536,, 2.0 \\
2,317,, 5.0 \\
2,279,, 5.0 \\
1,463,2.5 \\
1,088,4.0 \\
244,6.0 \\
212,, 5.0 \\
52,0.0
\end{array}
$$

$49,224,5.5$

$7,733,, 3.5$

$4,874,4.0$

$3,859,6.0$

$1,898,4.0$

$1,579,, 6.0$

$1,080,, 5.0$

$581,2.0$

$383,3.0$

$291,, 2.0$

$266,, 6.0$

$96,6.0$

$91,, 5.5$

$22,737,, 5.0$

$1,830,, 0.0$

$1,024,, 2.5$

$563,, 7.0$

$527,0.0$

$376,, 0.0$

$213,, 4.0$

$169,0.0$

$142,, 4.0$

$75,4.0$

$32,0.0$

$18,, 0.0$

$18,0.0$

4,989,,5.5

$317,, 6.0$

$273,, 4.5$

$210,, 0.0$

$163,, 3.0$

$85,4.0$

$64,4.0$

$48,, 0.0$

$21,, 6.0$

$7,050,, 7.5$
$1,184,, 3.5$

$7,050,7.5$

$85,187,, 3.0$ 